RFLP Report

\title{
TWO DINUCLEOTIDE REPEAT POLYMORPHISMS AT THE D8S1442 AND D8S1443 LOCI
}

\author{
Jun Nakura, ${ }^{1, *}$ Lin Ye, ${ }^{1}$ Koichi Kihara, ${ }^{1}$ Hidehisa Yamagata, ${ }^{1}$ \\ Kouzin Kamino, ${ }^{1}$ Yusuke NaKamura, ${ }^{2}$ Tetsuro MrKI, ${ }^{1}$ \\ and Toshio OGIHARA ${ }^{1}$ \\ ${ }^{1}$ Department of Geriatric Medicine, Osaka University Medical School, \\ 2-2 Yamadaoka, Suita 565, Japan \\ ${ }^{2}$ Human Genome Center, Institute of Medical Science, University of Tokyo, \\ 4-6-1 Shirogane-dai, Minato-ku, Tokyo 108, Japan
}

Two polymorphic dinucleotide (CA) repeat clones were isolated from cosmids, cCI8-1121 and cCI8-1199, mapped to chromosome 8p11.2-p12.

Key Words microsatellite, cosmid, chromosome 8

Two cosmids, cCI8-1121 and cCI8-1199, were digested completely with Sau3AI. Sau3AI-fragments were subcloned into BamHI site of pUC18 and screened on the basis of hybridization to a ${ }^{32} \mathrm{P}$-labeled poly $(\mathrm{dA}-\mathrm{dC}) \cdot$ poly $(\mathrm{dG}-\mathrm{dT})$ probe (Pharmacia) (Nagano et al., 1993). Positive subclones were partially sequenced and the sequences flanking a $(\mathrm{CA})_{\mathrm{n}}$ repeat were used to design PCR primers. Thus two dinucleotide repeat polymorphisms, M215 and M231 (Genbank accession number: G00-450-243), were isolated from the cosmids, cCI8-1121 and cCI8-1199, respectively.

Primers for $P C R$

M215-F $=5^{\prime}$-TGGTACTAGGTTGTGATGGTTACA- ${ }^{\prime}$

M215-R = 5'-ACAGGGCAGTTGTGAGATGTACT-3'

$\mathrm{M} 231-\mathrm{F}=5^{\prime}$-ACATTCAGCAGCGTTTTTCAG-3'

M231-R = 5'-GAGGAGCAACGTCTACTTCTG-3'

Polymorphism/frequency

M215 (D8S1443): Four alleles were detected in 30 chromosomes of unrelated Japanese individuals. Observed heterozygosity $=0.93$.

$\begin{array}{lll}\text { Allele } & \text { Size (bp) } & \text { Frequency } \\ \text { A1 } & 169 & 0.30 \\ \text { A2 } & 171 & 0.30 \\ \text { A3 } & 173 & 0.37 \\ \text { A4 } & 175 & 0.03\end{array}$

Received April 17, 1995; Revised version accepted July 12, 1995.

* To whom correspondence should be addressed. 
M231 (D8S1442): Six alleles were detected in 100 chromosomes of unrelated Japanese individuals. Observed heterozygosity $=0.52$.

$\begin{array}{lll}\text { Allele } & \text { Size (bp) } & \text { Frequency } \\ \text { A1 } & 111 & 0.01 \\ \text { A2 } & 117 & 0.16 \\ \text { A3 } & 119 & 0.01 \\ \text { A4 } & 121 & 0.20 \\ \text { A5 } & 123 & 0.60 \\ \text { A6 } & 125 & 0.02\end{array}$

Chromosomal localization. The cosmids, cCI8-1121 and cCl8-1199, have been localized to chromosome $8 \mathrm{p} 11.2$ and $8 \mathrm{p} 12$, respectively, by fluorescent in situ hybridization (Emi et al., 1992, 1993).

Mendelian inheritance. Mendelian inheritance was observed.

Amplification conditions. PCR reaction was carried out in a total volume of $10 \mu$ containing $50 \mathrm{ng}$ of genomic DNA, 4 pmol of one unlabeled primer, 4 pmol of a ${ }^{32} \mathrm{P}-\mathrm{ATP}$ end-labeled primer $(0.2 \mu \mathrm{Ci}), 200 \mu \mathrm{M}$ dNTP, $1 \%$ deionized formamide, $0.001 \%$ gelatin, $1.5 \mathrm{~mm} \mathrm{MgCl}_{2}, 50 \mathrm{mM} \mathrm{KCl}, 10 \mathrm{~mm}$ Tris- $\mathrm{HCl}$ at $\mathrm{pH} 8.4$ and $0.25 \mathrm{U}$ Taq polymerase, using a Perkin Elmer Cetus Thermal Cycler for 35 cycles as follows: $94^{\circ} \mathrm{C}$ for $45 \mathrm{sec}$, annealing temperature $\left(47^{\circ} \mathrm{C}\right.$ for $\mathrm{M} 215$ and $57^{\circ} \mathrm{C}$ for M231) for $30 \mathrm{sec}$, and $72^{\circ} \mathrm{C}$ for $30 \mathrm{sec}$ for each cycle. The amplified product was fractionated in a $6 \%$ polyacrylamide gel containing $30 \%$ formamide and visualized by autoradiography. The size of the alleles was determined by comparison to M12mp18 DNA sequencing ladders.

Acknowledgments This work was partly supported by a Grant-in-Aid for Creative Basic Research (Human Genome Program) from the Ministry of Education, Science and Culture of Japan, and a grant of the Research Project on Health and Aging.

\section{REFERENCES}

Emi M, Takahashi E, Koyama K, Okui K, Oshimura M, Nakamura Y (1992): Isolation and mapping of 88 new RFLP markers on human chromosome 8. Genomics 13: 1261-1266

Emi M, Fujiwara Y, Nakamura Y (1993): A primary genetic linkage map of 14 polymorphic loci for the short arm of human chromosome 8. Genomics 15: 530-534

Nagano K, Nakura J, Kihara K, Ye L, Kamino K, Mistuda M, Ohta T, Jinno Y, Niikawa N, Miki $\mathrm{T}$, Ogihara $\mathrm{T}$ (1993): Isolation and mapping of microsatellites from a library microdissected from the Werner's syndrome region, 8p11.2-p22. Jpn J Human Genet 38: 391-397 